\title{
KEYNOTE SPEAKER ABSTRACTS
}

\section{Tropical brown algae immunostimulants in aquaculture}

\author{
Alim Isnansetyo \\ Department of Fisheries, Faculty of Agriculture, Universitas Gadjah Mada Jl. Flora, Bulaksumur, Yogyakarta, Indonesia
}

\begin{abstract}
The global growth of aquaculture is the highest among the agribusiness sectors, and became the major supply of human seafood consumption since the early 1990s. The high growth of aquaculture faces the serious challenge on the fish health management especially in the prophylactic countermeasure of fish diseases. Immunostimulant have recently attract more attention of scientists and aquaculturist as well as fish farmers due to the technically practical use from small to large scale aquaculture either in hatchery or growth out stages. The tropical brown algae are the potential resources for marine immunostimulant especially alginate and fucoidan. This paper focuses on the development of alginate and fucoidan extracted from tropical brown algae. Alginate improved the non-specific immunity of catfish, tilapia and shrimp by increasing the several degrees of humoral and cellular immune parameters. The increases in the immunity were confirmed by the increase in the resistance of tilapia, catfish and shrimp against Streptococcus sp., Aeromonas hydrophila and White Spot Syndrome Virus (WSSV). The similar results were also obtained by using the fucoidan. The molecular evidence were also proved by the up-regulation of immune genes in shrimp. The recent results imply the promising use of alginate and fucoidan for fish health management in aquaculture.
\end{abstract}

\section{More research and education in aquaculture for sustainable seafood and nutrition security}

$\operatorname{Ram} C$. Bhujel

Aqua-Centre, School of Environment, Resources and Development (SERD) Asian Institute of Technology (AIT), Thailand

\begin{abstract}
Currently world population is growing by one billion almost each decade exerting huge pressure on all the natural resources. This increased population requires additional 20 million $\mathrm{mt}$ of seafood each decade. Assuming wild fish catch remains constant and aquaculture has to cover this, it has to growth by $25 \%$ per decade from the current aquaculture production i.e. 80 million $\mathrm{mt} / \mathrm{year}$. Aquatic food is already the no. 1 source of protein. Globally 140 million $\mathrm{mt}$ is consumed annually whereas the nearest rivals chicken, pork and beef are at 120,115 and 70 million $\mathrm{mt}$ respectively. Not realizing this fact, most policy makers and public in many countries have given low priority to aquaculture and fisheries compared to other agriculture sub-sectors. It is mainly due to lack of scientific knowledge, information and political will. Asian countries need to worry more as they account for over $60 \%$ of the fast growing global population. Some of the populous countries; namely, China (1,388 million), India (1,342 million), Indonesia (263 million), Pakistan (197 million) and Bangladesh (165 million) are facing critical challenges of food shortages. The three most populous countries such as China, India and Indonesia with 3 billion people will probably need supply of additional 30 million $\mathrm{mt}$ of seafood annually within a decade. The latest UNICEF data show that children of several Asian countries are already suffering from stunting e.g. $45 \%$ in Pakistan, $38 \%$ in India and $36 \%$ in Indonesia and also $36 \%$ in Bangladesh. Kids in rural communities suffer even more. To reduce malnutrition,
\end{abstract}


nutrients from aquatic animals are the most effective ones for children, which can be supplied either in fresh or processed forms e.g. powder, paste, soup etc. They are also easy to grow in backyard ponds and often the cheapest source available. Therefore, scope of seafood will be realized and its demand is going to skyrocket in Asia and globally. Some argue that due to population pressure innovative food production technologies have been developed in Asia especially in aquaculture sector. About $90 \%$ production comes from a wide range of species are grown in Asian countries; namely; carps, catfishes, tilapia, snakehead, milk fish, sea bass, groupers, shrimps, prawn, crabs, oysters, mussels, cockles, and seaweeds. Some of the technologies have developed through research and commercialization is occurring on a mass scale. There are almost similar success stories. as in the case of Salmon industry in Norway e.g. production of over 400 tons of Pangasius per ha in 6 months in Vietnam, production of over 30 million mono-sex tilapia fry per month, 20 tons of tilapia in a single cage in Vietnam, 30 tons of white shrimp per ha, and supply of 4 tons of snakehead fish daily by a single farm in Thailand. As a result many products of these species are available in the local as well as international markets all over the world. Ground breaking innovations and adaptation yet to be explored in aquaculture to develop new technologies and also boost the productivity of existing systems utilizing advanced technologies such as artificial intelligence (AI), internet of things (IoT), remote sensors, block chain technologies and so on. All researchers, educators, extension workers, policy makers and planners should realize the future scope of seafood and its industry growth potential and work jointly. At the same time when industry grows it faces several challenges such as environmental degradation. Challenges from global warming and climate change are already there. Therefore, industry needs smart solutions, for that we need smarter youths for the sector to carry out more research. Aquaculture Fisheries sector is the best choice for their degrees. We need to convince them that our health comes first. Therefore, we have been consistently working on developing curricula on seafood and nutrition security in Asia and globally. More collaborative efforts are needed for research and education in this sector similar to what we are launching a project with partners in Indonesia, Vietnam and European countries.

\title{
Remediation and production of valuable biomass
}

\author{
Nikolai Borisjuk \\ Jiangsu Collaborative Innovation Centre of Regional Modern Agriculture \& Environmental Protection, the School of Life \\ Science, Huaiyin Normal University, Huaian, China
}

\begin{abstract}
Pollution and shortages in clean water supplies are among the most serious problems that humanity is facing. Eutrophication of reservoirs by municipal, industrial and agricultural pollutants is a global concern and has been identified as a major environmental problem for water resource management. As an inexpensive and ecofriendly method, the cultivation of aquatic plants is attractive for the restoration of eutrophic water bodies by removal of excessive by nutrient such as Nitrogen, Phosphorus fertilizers and other chemicals. Among aquatic plants, the tiny duckweed plants are especially efficient in water remediation due to their high growth rate and an ability to cover the whole water surface. Duckweeds are represented by 37 species of the Lemnaceae family, with wide distribution around the globe. Duckweed can accumulate up to $9 \mathrm{t} / \mathrm{ha} /$ year of total nitrogen and $0.8 \mathrm{t} / \mathrm{ha} /$ year of total phosphorus in their biomass, producing 80-100 tons of dry mass per hectare per year, which is over 5 times as high as maize. With high content of protein and starch, the produced duckweed biomass has excellent nutrition qualities both for animals and humans, as it has been demonstrated in numerous studies on fishes, dairy cows, pigs, sheep, goats, and poultry. The studies have shown that the protein intake can be partially or completely substituted by duckweed without impeding growth. Duckweed biomass is most widely use as feed for fish, it can be consumed in a fresh green or dry state and is suitable for both herbivorous and omnivorous fish species. Moreover, taking advantage of the recent progress in biotechnology and genomics, duckweed is a promising platform for
\end{abstract}


producing immunological proteins with the potential to protect animal and aquaculture

livestock against various pathogens.

\title{
Marine ecological exploration of Kiribati in South Pacific
}

Hyung Geun Kim

Dept. of Marine Bioscience, Gangneung-Wonju National University, Gangneung , Gangwondo, Korea

\begin{abstract}
At the coast of potential OTEC (Ocean Thermal Energy Conversion) site on Tarawa island of Republic of Kiribati, South Pacific, the marine ecological survey was investigated in July 2016. Take this opportunity to share with Kiribati people how to cultivate and make strain useful seaweeds in SSUA (Sustainable Seawater Utilization Academy) Program. SSUA is a collaboration between KRISO (Korea Research Institute of Ships and Ocean Engineering), USP (University of South Pacific) and SPC (The Pacific Community), (KTI) Kiribati Institute of Technology which was funded by KOICA in 2016. Coral reef in Kiribati coast, 300 500m from the coast line, is connected to the land with coral reef flat and extends outwards to the ocean as reef slope. At the coral reef flat sites, point 1 and 3, foliose seaweed such as Enteromorpha, Sagassum, Hypnea and Laurencia were found. At the fore-reef slope point 2, due to the waves, much formation of seaweed living on coral reefs was found other than foliose type. Acropora was also going well at point 2. In lagoon, only remains of coral reefs were found without much biodiversity and only one coral reef species was found. On the outside of the Boniriki coastal basin, point 5 as control site, the growth of various coral organisms can be seen, and a crawling morphology of the species such as Halimeda and Gelidium, attached to the coral. At point 5, more diversity of seaweed living on coral reefs was seen compared to points 1,2 and 3. Kiribati coast is destroyed due to coastal development and increasing number of tourists. The Korean ambassador, Sung In Kim (2016) said that people cut off the mangroves that make their way to the shore. Mangrove can't supply nutrients to coral reef and it ultimately leads to their death.
\end{abstract}

\section{Malaysian fermented fish products}

Nurul Huda

Faculty of Food Science and Nutrition, Universiti Malaysia Sabah

\begin{abstract}
In 2017, Malaysia landed around 1,465,113 tons of marine fish, which mainly contribute by Peninsular Malaysia which reaches around $76.5 \%$ of the total landing of marine fish in Malaysia (Department of Fisheries 2018). The majorities of landed marine fish (63\%) are consumed while fresh; the rest is frozen $(1 \%)$, cured $(11 \%)$, made into fish-meal $(20 \%)$ or disposed of by other means $(5 \%)$. The category of cured fish includes dried/salted/smoked products $(28 \%)$, steamed/boiled products $(5 \%)$, fermented products $(28 \%)$ and other products such as fish crackers and fish balls $(39 \%)$. The most significant fermented fish product produced in Malaysia is belacan, followed by budu and cincalok. Another fermented fish product produced in Malaysia is pekasam. This paper will describe the processing method, composition and quality characteristics of Malaysian fermented fish products.
\end{abstract}




\title{
Utilization of fish industry by-products - a link for implementing research into industrial application
}

Kanokrat Limpisophon

Kasetsart University, Thailand

\begin{abstract}
FAO (2018) reported that in 2016 over 151 million tons of total fish were utilized for human consumption. By-products from processing industries are defined as leftover materials after fish is processed via different industrial processes. Fish byproducts such as skin, head, frame, fillet cut-offs, bone, viscera, blood may constitute up to $70 \%$ of the whole fish. These cannot be consumed directly. Utilization of fish byproducts has gaining attention over the past two decades which is in line with UN Sustainable Development Goals (SDGs) that aim to halve food waste by 2030 . Utilization of fish by-products can be categorized into three groups, i.e., new (valueadded) food products, high-value functional ingredients, and non-food product ingredients. Quantity and quality of by-product material, and nutritional aspects of finished food product should be considered for R\&D project. Examples of by-products utilization to be discussed are edible film, high-calcium snack from salmon bone, innovative tuna blood powder. There are required appropriate approaches for translational research to industry. Implement from University research to industrial practice involves understanding of Technology Readiness Level (TRL) of the available research, i.e., how far before it will attain commercial practice level. Additional key success factors for translational research to industry application are 1) mutual trust and understanding between university researcher and industry liaison, 2) open and transparent communication for commitment, 3) IP (intellectual property) and share benefit (and risk) issues among parties. In addition, government can act as a key driver, to facilitate and promote academia-industry collaboration for innovation.
\end{abstract}

\section{Mutual reinforcement between integrated coastal management \& marine spatial planning in Xiamen}

Xiongzhi Xue

Xiamen University, China

\begin{abstract}
Integrated Coastal Management (ICM) is a natural resource and environmental management system that employs an integrative, holistic approach and an interactive planning process in addressing complex management issues in coastal areas. Marine Spatial Planning (MSP) is a process of analysing and allocating marine spaces to specific uses, to achieve ecological, economic and social objectives that are usually specified through the political process. Xiamen has implemented ICM for 25 years and the operational methodology was recognized as a successful ICM model. Xiamen's MSP, namely Xiamen Marine Functional Zoning Scheme, was implemented under the development of ICM, it was a part of Xiamen's ICM legislation and enforcement capacity building, and has made great contribution to the rational utilization of marine resources, effective conservation of marine ecological environment and sustainable social economic development over the years. Xiamen's experiences proved that there is a mutual reinforcement relationship between ICM and MSP. ICM can help guaranteeing the implementation of MSP, while MSP is an important component and tool of ICM which could satisfy well one of the ICM integration goal, spatial integration, MSP could also provide guidance for further ICM implementation.
\end{abstract}




\title{
Restoration and conservation of kelp forests in Korean coasts
}

Kim Jeong Ha, Kwon Mo Yang, Byung Hee Jeon*, Moon Jung Kim, Dong Seok Lee Department of Biological Sciences, Sungkyunkwan University, Suwon, Korea

*Ecological Restoration Section, Korean Fisheries Resources Agency

\begin{abstract}
Korean east coast has been suffering marine deforestation last decades, comprising about $60 \%$ of all rocky shallow subtidal area, with the average density of urchins 7.8 individuals $/ \mathrm{m} 2$ in the completely barren sites. Experimental manipulation of sea urchin density was conducted on the nine natural bedrocks of barren condition, each separated by sandy barriers in between. Three experimental conditions were applied: all urchin removal, "half"- removal, control for no-removal. At all removal sites, macroalgal community was recovered in good shape for three consecutive spring seasons (2015-2017), whereas barren state continued at the no-removal control sites. For the "half"-removal condition, we started with 4.0 individuals $/ \mathrm{m} 2$, and then switched to 2.5 individuals $/ \mathrm{m} 2$ to achieve an optimal density level, which may be necessary for the maintenance of kelp forest. A larger scaled approach is on-going to test a few more hypothesis, such as function of other herbivores and transplanting. We also try to test food web complexity for the newly recovered forests in comparison with existing old forests using stable isotope. In the case of Jeju coast, where sea urchin is not common, barren condition is presumably caused by multiple stress factors. We applied the metapopulation concept to artificial reefs (with different substrate types) to improve the chance of natural recruitment of seaweeds as the function of distance from nearby existing source kelp beds. The experimental design and on-going results will be introduced in the presentation.
\end{abstract}

